\title{
Verifying a Computational Method for Predicting Extreme Ground Motion
}

\author{
R. A. Harris, ${ }^{1}$ M. Barall, ${ }^{1,2}$ D. J. Andrews, ${ }^{1}$ B. Duan, ${ }^{3}$ S. Ma, ${ }^{4}$ E. M. \\ Dunham, ${ }^{5}$ A.-A. Gabriel, ${ }^{6}$ Y. Kaneko, ${ }^{7}$ Y. Kase, ${ }^{8}$ B. T. Aagaard, ${ }^{1}$ D. D. \\ Oglesby, ${ }^{9}$ J.-P. Ampuero, ${ }^{10}$ T. C. Hanks, ${ }^{1}$ and N. Abrahamson ${ }^{11}$
}

\section{INTRODUCTION}

Large earthquakes strike infrequently and close-in recordings are uncommon. This situation makes it difficult to predict the ground motion very close to earthquake-generating faults, if the prediction is to be based on readily available observations. A solution might be to cover the Earth with seismic instruments so that one could rely on the data from previous events to predict future shaking. However, even in the case of complete seismic data coverage for hundreds of years, there would still be one type of earthquake that would be difficult to predict: those very rare earthquakes that produce very large ground motion.

These extreme-ground-motion events are so unlikely that most engineers would not even consider designing facilities to withstand the possibility of their occurrence. An exception would be a structure that needs to remain functional for an unusually long period of time. One example of a planned longlife structure has been the high-level nuclear waste repository at Yucca Mountain, Nevada. This structure has been envisioned as one that would perform reliably over tens of thousands of years (CRWMS M\&O, 1998).

The problem of predicting the maximum possible ground motion in the Yucca Mountain region has been studied using two approaches: a geological approach that examines evidence from the past, and a seismological approach that predicts possibilities for the future via computer simulations. Both strategies are described in detail in Hanks et al. (forthcoming). The seismological approach involved computer simulations that invoked a "physical limits" perspective. Calculations were per-

\footnotetext{
1. U.S. Geological Survey

2. Invisible Software

3. Texas A\&M

4. San Diego State University

5. Stanford University

6. ETH, Zurich

7. University of California, San Diego

8. Geological Survey of Japan

9. University of California, Riverside

10. California Institute of Technology

11. Pacific Gas and Electric Company
}

formed to numerically simulate the largest possible earthquakegenerated ground motions that could occur, while remaining faithful to the current state of knowledge about rock physics and wave propagation. These "physical limit" simulations were specifically applied to scenario earthquakes on the faults on and near Yucca Mountain (Andrews et al. 2007). In this paper we report on an exercise to verify the computer code that was used to produce these results. Our procedure of computer code comparisons may be adopted for other situations where sufficient data are lacking and analytic solutions are also unavailable to confirm the results.

\section{THE SCEC-USGS DYNAMIC EARTHOUAKE RUPTURE CODE VERIFICATION PROJECT}

The objective of the Southern California Earthquake Center (SCEC)-U.S. Geological Survey (USGS) Dynamic Earthquake Rupture Code Verification Project is to test the computer codes that are used by scientists to numerically simulate earthquake ruptures. These computer codes are complex, and there are no analytic solutions for this type of scientific problem, except in the very specialized case where a numerically simulated earthquake starts, then travels outward at a constant speed, forever (Kostrov 1964; Madariaga 2007). Ideally these earthquake simulation codes would be tested against data, such as seismological ground-motion recordings, but it is often the case, especially very close to large earthquakes, that such data do not exist. The next best option given the lack of data is to perform an inter-code comparison, a code verification exercise, and that is what this paper describes. Now in its seventh year, the SCEC-USGS Dynamic Earthquake Rupture Code Verification Project (http://scecdata.usc.edu/cvws; Harris et al. 2009) has provided more than 20 benchmark exercises that computer modelers can use to compare the earthquake simulation results produced by their own computer codes with those produced by others. The results that are compared include synthetic ground motions and images of the time-dependent progress of earthquake slip on a fault surface.

The project's benchmark exercises have been developed using a step-by-step approach, with each subsequent bench- 
mark involving an incremental change relative to previous benchmarks. Our goal is to make it possible to easily spot earthquake-simulation results that are inconsistent with the assumptions upon which they are built, and to thereby illuminate computer code errors. Without this code-comparison testing, these erroneous earthquake-simulation results might have been hailed as new scientific discoveries about earthquakes.

To date, the sequence of benchmark exercises has evolved from fairly homogeneous and simple problems to those that incorporate more complexity in stress, materials, friction, and fault geometry, the four building blocks of a dynamic rupture simulation (e.g., Harris 2004). Many of the benchmarks have assumed simple friction on a vertical strike-slip fault and initial stress conditions that lead to subshear (slower than the shearwave velocity) earthquake rupture speeds, but some of the benchmarks have varied from these conditions (http://scecdata.usc.edu/cvws/benchmark_descriptions.html).

In this paper we describe two of the project's benchmark exercises that were specifically designed to test the code that was used to predict earthquake-generated extreme (maximum possible) ground motion. These benchmarks targeted the particular case of earthquake rupture on a normal fault at Yucca Mountain, Nevada (Figure 1). This fault region has been suggested as the location of the United States of America's highlevel nuclear waste repository, although at the time of this writing (early 2011), the nation's plans for the repository are on hold. We refer the reader to a number of reports including Winograd (1974), Bechtel SAIC Company (2004, 2005), and Hanks et al. (1999, 2006, forthcoming) for detailed information about extreme ground motions and the Yucca Mountain project.

\section{TESTING THE CODE USED TO PREDICT EXTREME GROUND MOTION}

Andrews et al. (2007) numerically simulated dynamic earthquake rupture to calculate peak ground velocities at Yucca Mountain. As with any scientific experiment, it is important to check that the experiment is repeatable and the method is robust. Thus were born the dynamic rupture benchmark exercises "The Problem, Version 12 (TPV12)" and "The Problem, Version 13 (TPV13)" (http://scecdata.usc.edu/cvws/benchmark_descriptions.html; Figure 2).

The goal of these two benchmark exercises, TPV12 and TPV13, was to test if other two-dimensional computer codes would produce the same results as the code used by Andrews et al. (2007), for a Yucca Mountain-type science problem. The TPV12 and TPV13 benchmark exercises do not use exactly the same assumptions as those that were implemented in the Andrews et al. (2007) paper. Instead a simplified set of assumptions (Table 1; Figure 2) for rupture on a normal fault were implemented in all of the participating computer codes, including the 2D code used in the Andrews et al. (2007) paper. A comprehensive description of each of the benchmarks, which can be used by any researcher to repeat our efforts, is available at http://scecdata.usc.edu/cvws/benchmark_descriptions.html.

\section{THE BENCHMARKS}

The benchmark exercises TPV12 and TPV13 both assume a 60-degree dipping normal fault, based on the dip of Yucca Mountain's Solitario Canyon fault, and initial stress conditions that lead to large stress-drop supershear rupture. The primary difference between the two benchmarks is that in TPV12 the fault is set in an elastic material, whereas in TPV13 the fault is set in a plastic material. Both benchmarks TPV12 and TPV13 have 2D and 3D options. With TPV12 and TPV13, in addition to assessing whether or not the $2 \mathrm{D}$ code that was used in the Andrews et al. (2007) paper would produce the same results as the other codes when doing the same science problem, we also tested two hypotheses. The first is that $3 \mathrm{D}$ computations produce smaller values for the peak ground motions than $2 \mathrm{D}$ computations. The second is that plastic yielding reduces the peak ground motions.

\section{THE CODES}

The SCEC-USGS TPV12 and TPV13 benchmark exercises were conducted by 10 members of the SCEC-USGS group, each of whom used a different spontaneous earthquake-rupture computer code. Some of the modelers performed only one of the TPV12 and TPV13 benchmarks, some performed only the $2 \mathrm{D}$ versions, some performed only the $3 \mathrm{D}$ versions; also, not all of the modelers computed the results at the many seismic station locations listed in the SCEC-USGS TPV12 and TPV13 benchmark assignment. In this paper, the results that are shown are those from all of the modelers and codes that did the calculations at a seismic station at the designated repository site, which is assumed to be $1 \mathrm{~km}$ (horizontal perpendicular distance) from the fault at $300 \mathrm{~m}$ depth, since this location is in the vicinity of some of the Andrews et al. (2007) simulations. Table 2 lists the codes that performed the benchmarks at the specific site; six codes (including the Andrews code that was used in the Andrews et al. 2007 paper) performed the elastic 2D benchmark, six codes performed the elastic 3D benchmark, six codes (including the Andrews code) performed the plastic 2D benchmark, and four codes performed the plastic 3D benchmark.

\section{RESULTS}

Figures 3 and 4 show the synthetic seismograms produced by our extreme-ground-motion benchmark simulations at the repository station. The seismograms have been filtered with an acausal two-poles, two-passes $3-\mathrm{Hz}$ lowpass Butterworth filter, with $3 \mathrm{~Hz}$ chosen because it is the resolution limit for the computer simulations. Our overall qualitative findings are threefold. First, five computer codes that performed the 2D benchmark exercises, TPV12-2D and TPV13-2D, produced synthetic ground motions similar to those generated by the (2D) Andrews code. This demonstrates that the Andrews code was functioning as expected. Second, the 3D benchmarks, TPV12 and TPV13, led to smaller peak ground velocities (PGV) than the 2D benchmarks, TPV12-2D and TPV13-2D (Tables 3 and 


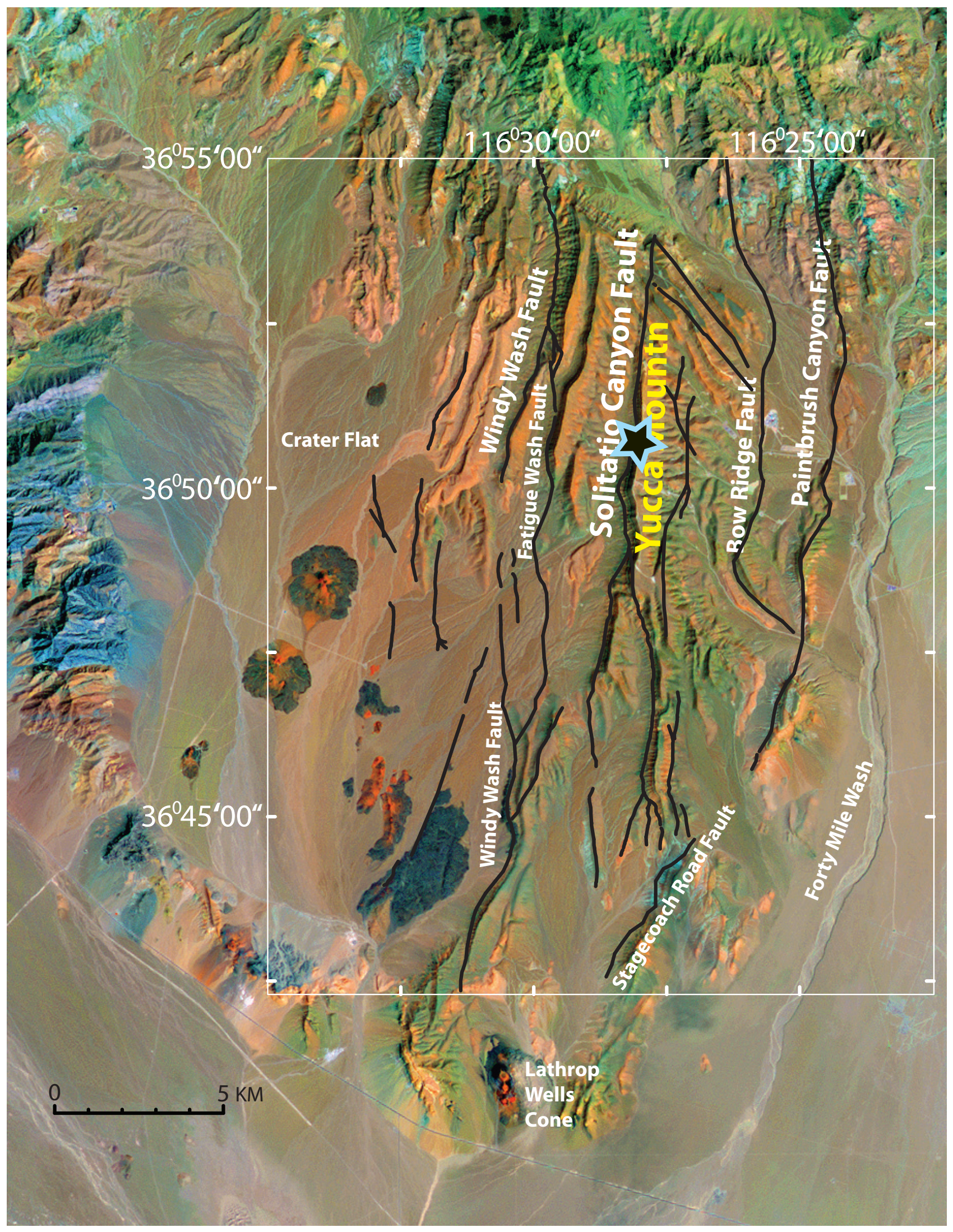

A Figure 1. Geographic setting of the Solitario Canyon fault and the designated site of the nation's high-level nuclear waste repository at Yucca Mountain. The designated repository site (star) is $300 \mathrm{~m}$ below Yucca Mountain, in the footwall of the Solitario Canyon fault. This figure is slightly modified from Figure 7 of Andrews et al. (2007). 


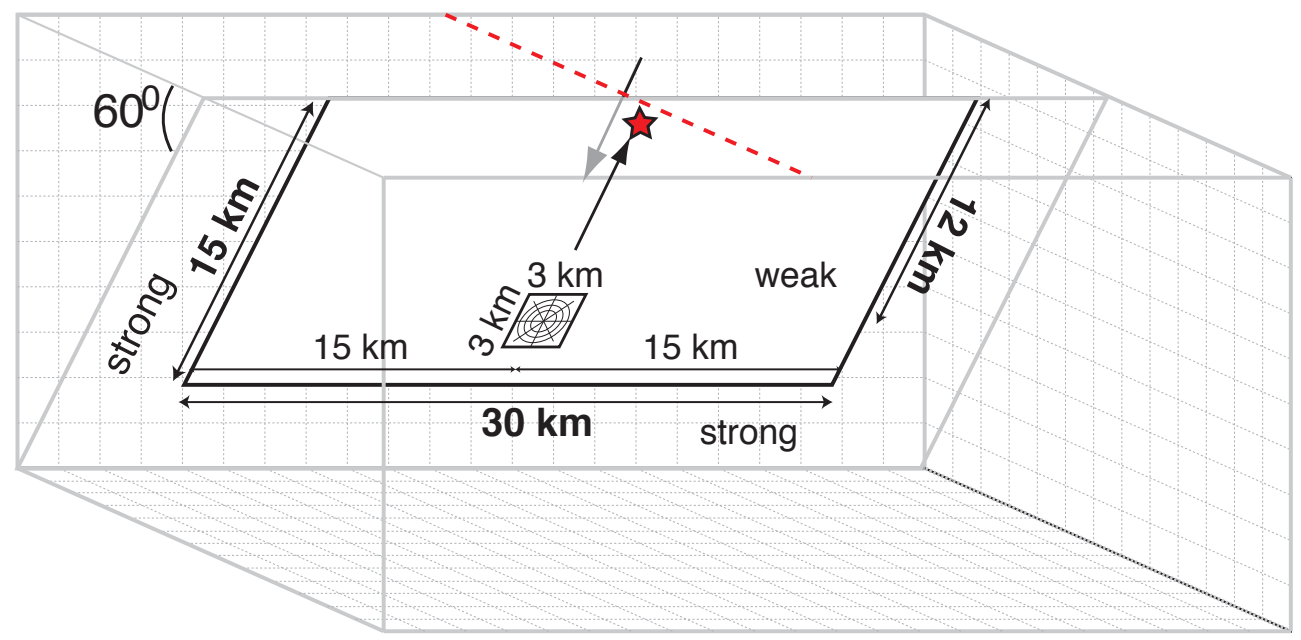

$\Delta$ Figure 2. The fault geometry for the 3D benchmarks TPV12 and TPV13. The 30-km along-strike $\times 15-\mathrm{km}$ along-dip normal fault dips 60 degrees. Earthquake rupture propagation is not allowed beyond this $30-\mathrm{km} \times 15-\mathrm{km}$ area due to strong sections that act as a barrier to rupture and surround the fault plane on two sides and below the fault. Nucleation is centered along-strike, in a $3-\mathrm{km} \times 3-\mathrm{km}$ patch at 12 $\mathrm{km}$ down-dip. The red star indicates the location of a (hypothetical) seismic station in the designated repository site (see Figure 1 for a map view of this location) where synthetic seismograms are calculated. Synthetic seismograms at this station are shown in Figures 3 and 4. The seismic station is in the footwall of the normal fault, and is at $0 \mathrm{~km}$ along-strike from the hypocenter, and $0.3 \mathrm{~km}$ depth, $1 \mathrm{~km}$ perpendicular horizontal distance from where the fault is at $0.3 \mathrm{~km}$ depth. The red dashed line indicates a line perpendicular to the fault trace, $0 \mathrm{~km}$ along strike from the hypocenter. The 2D models TPV12-2D and TPV13-2D start at the earth's surface where this dashed line intersects the fault trace and extend along-dip to the bottom of the 3D fault. The material velocities and density of the rocks surrounding the fault are assumed homogeneous.

4). Third, the plastic yielding assumption in both the $2 \mathrm{D}$ and 3D formulations of benchmark TPV13 led to smaller PGV for the vertical component of motion than the TPV12 benchmarks that assumed elastic off-fault response (Table 3). However, for the horizontal, fault-perpendicular component of motion, only the 2D formulation produced a smaller PGV value for the plastic benchmark compared to the elastic benchmark (Table 4).

\section{MISMATCH CALCULATION}

We don't know what the correct answer is to the benchmark exercises that we have posed, because there is no analytical solu- tion, and we also don't know that any specific computer code works better than any other specific computer code. What we can do is to quantitatively examine the amount of difference among the results by performing a mismatch calculation. A rule of thumb might be that a 10-20\% mismatch of computed seismic motion at a specific station is satisfactory, whereas a greater mismatch is excessive and suggests errors or inconsistencies in one or more of the codes. For this calculation we specifically examine the PGV, since it has been a parameter of interest for the repository design.

We calculate the mismatch at our seismic station as the difference in PGV between the maximum PGV value produced by

TABLE 1

Some of the Basic Assumptions in TPV12 and TPV13 (for complete details see http://scecdata.usc.edu/cvws)

\begin{tabular}{ll}
\hline Material velocities and densities & Homogeneous \\
Fault dip & Constant 60 degrees \\
Fault down-dip dimension & $15 \mathrm{~km}(0$ to $15 \mathrm{~km})$ \\
Fault along-strike dimension & $30 \mathrm{~km}$ \\
Nucleation area for 3D & $3 \mathrm{~km} \mathrm{x} 3 \mathrm{~km}$ \\
Nucleation region for 2D simulations & $3 \mathrm{~km}$ \\
Nucleation location for 3D simulations & Centered along-strike at $12 \mathrm{~km}$ down-dip distance from the earth's surface \\
Nucleation location for 2D simulations & $12 \mathrm{~km}$ down-dip distance from the earth's surface \\
Frictional failure criterion & Slip-weakening \\
Initial on-fault stress conditions & Depth-dependent \\
Off-fault response & Elastic for TPV12 \\
Off-fault response & Plastic for TPV13 \\
Plastic assumptions & Yielding in shear with non-associative Drucker-Prager \\
\hline
\end{tabular}


(A)

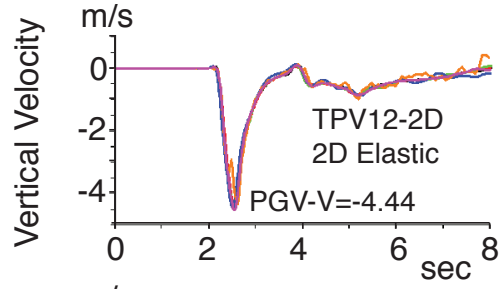

(B)

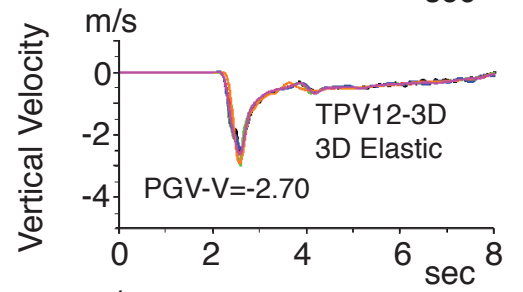

(C)

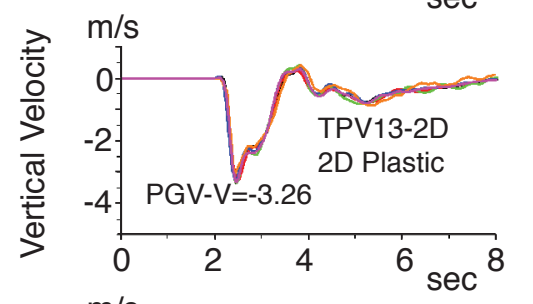

(D)

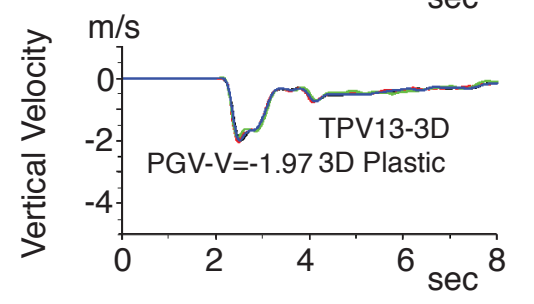

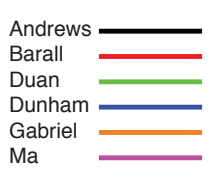

Aagaard

Barall

Duan

Kaneko

Kase

$\mathrm{Ma}$

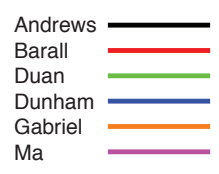

Barall

Duan

Kaneko

$\mathrm{Ma}$
(A)

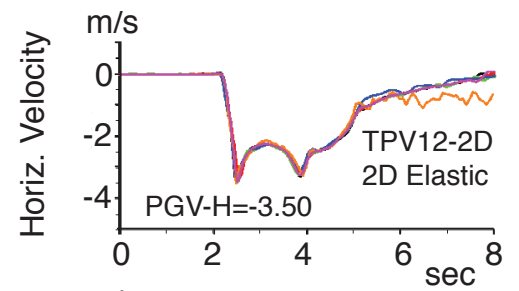

(B)

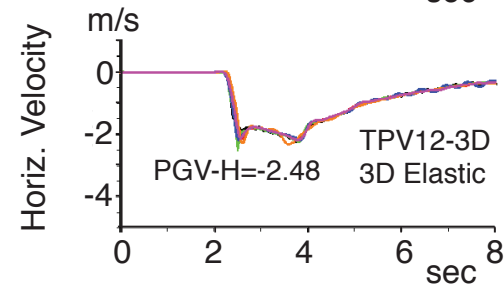

(C)

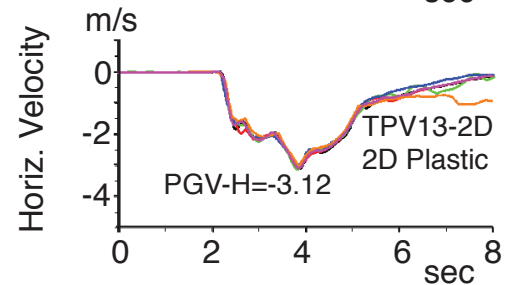

(D)

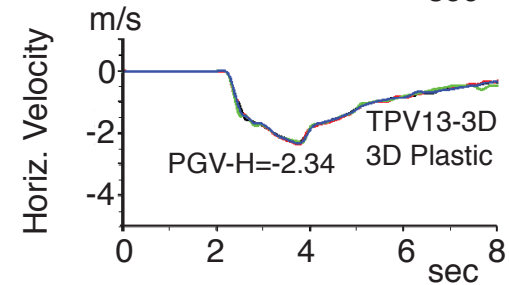

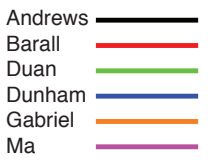

Aagaard Barall Duan Kaneko Kase $\mathrm{Ma}$

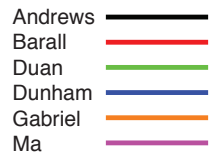

Barall Duan Kaneko $\mathrm{Ma}$
A Figure 3. Simulated vertical ground motion (velocity vs. time) at our seismic station $1 \mathrm{~km}$ away from the fault at $300 \mathrm{~m}$ depth. PGV-V is the peak vertical value. It is the average of the peakvalues among all the codes' results (Table 3). Each colored curve represents a different spontaneous-rupture code that was used to do the simulation. (A), (B), (C), and (D) are the results for 2D elastic, 3D elastic, 2D plastic, and 3D plastic simulations, respectively. The black curves in $(A)$ and $(C)$ are the results using the Andrews SCOOT code. The seismograms have been filtered with an acausal two-poles, two-passes, $3-\mathrm{Hz}$ lowpass Butterworth filter.
A Figure 4. Simulated horizontal ground motion (velocity vs. time) at our seismic station $1 \mathrm{~km}$ away from the fault at $300 \mathrm{~m}$ depth. PGV-H is the peak horizontal (in the direction perpendicular to the fault trace) value. It is the average of the peak values among all the codes' results (Table 4). Each colored curve represents a different spontaneous-rupture code that was used to do the simulation. (A), (B), (C), and (D) are the results for $2 \mathrm{D}$ elastic, $3 \mathrm{D}$ elastic, $2 \mathrm{D}$ plastic, and $3 \mathrm{D}$ plastic simulations, respectively. The black curves in (A) and $(C)$ are the results using the Andrews SCOOT code. The seismograms have been filtered with an acausal two-poles, two-passes, 3-Hz lowpass Butterworth filter.

\section{TABLE 2}

Modelers and codes used to perform TPV12 and TPV13 benchmark exercises at the repository station (for complete details see http://scecdata.usc.edu/cvws). A mark of " $x$ " indicates the code was used to perform the benchmark, and the results are shown in Tables 3 and 4 and Figures 3 and 4.

\begin{tabular}{|lllcccc|}
\hline & & & TPV12 & TPV12 & TPV13 & TPV13 \\
Modeler & Code & Code Reference & 2D & 3D & 2D & 3D \\
Andrews & SCOOT & Andrews et al. 2007 & $\mathrm{x}$ & & $\mathrm{x}$ & \\
Aagaard & EqSim & Aagaard et al. 2004 & & $\mathrm{x}$ & & \\
Barall & FaultMod & Barall 2009 & $\mathrm{x}$ & $\mathrm{x}$ & $\mathrm{x}$ & $\mathrm{x}$ \\
Duan & EOdyna & Duan 2008; 2010 & $\mathrm{x}$ & $\mathrm{x}$ & $\mathrm{x}$ & $\mathrm{x}$ \\
Dunham & FDMAP & Dunham forthcoming & $\mathrm{x}$ & & $\mathrm{x}$ & \\
Gabriel & SEM2DPACK & Ampuero 2009 & & $\mathrm{x}$ & \\
Kaneko & SPECFEM3D & Kaneko et al. 2008 & & $\mathrm{x}$ & & $\mathrm{x}$ \\
Kase & Kase & Kase Kuge 2001 & & $\mathrm{x}$ & & \\
Ma & MAFE & Ma 2009; Ma and Andrews 2010 & $\mathrm{x}$ & $\mathrm{x}$ & $\mathrm{x}$ & $\mathrm{x}$ \\
\hline
\end{tabular}


TABLE 3

PGV-vertical (also see Figure 3). All seismograms were first filtered with an acausal two-poles, two-passes, $3-\mathrm{Hz}$ lowpass Butterworth filter

\begin{tabular}{|c|c|c|c|c|}
\hline Benchmark & $\begin{array}{l}\text { PGV- } \\
\text { Maximum } \\
(\mathrm{m} / \mathrm{s})\end{array}$ & $\begin{array}{l}\text { PGV- } \\
\text { Minimum } \\
(\mathrm{m} / \mathrm{s})\end{array}$ & $\begin{array}{l}\text { PGV- } \\
\text { Average } \\
\text { (m/s) }\end{array}$ & $\begin{array}{l}\text { Mismatch } \\
\text { (equation } \\
\text { 1) }\end{array}$ \\
\hline $\begin{array}{l}\text { TPV12-2D } \\
\text { elastic }\end{array}$ & 4.52 & 4.32 & 4.44 & $4 \%$ \\
\hline $\begin{array}{l}\text { TPV13-2D } \\
\text { plastic }\end{array}$ & 3.34 & 3.09 & 3.26 & $8 \%$ \\
\hline $\begin{array}{l}\text { TPV12-3D } \\
\text { elastic }\end{array}$ & 2.97 & 2.49 & 2.70 & $17 \%$ \\
\hline $\begin{array}{l}\text { TPV13-3D } \\
\text { plastic }\end{array}$ & 2.04 & 1.89 & 1.97 & $7 \%$ \\
\hline \multicolumn{5}{|c|}{$\begin{array}{l}\text { Results: The peak ground velocities from the } 2 \mathrm{D} \text { simula- } \\
\text { tions are larger than those from the } 3 \mathrm{D} \text { simulations, and } \\
\text { the elastic simulations produce larger peak ground veloci- } \\
\text { ties than the corresponding plastic simulations. }\end{array}$} \\
\hline
\end{tabular}

any of the codes and the minimum PGV value produced by any of the codes, and divide this difference by the PGV's average value among the codes, thereby producing a normalized value:

Mismatch at station $=\frac{\max (\mathrm{PGV})-\min (\mathrm{PGV})}{\text { average }(\mathrm{PGV})}$.

We perform the mismatch calculation independently for each of the three components of ground motion at the seismic station: vertical, fault-perpendicular horizontal, and fault-parallel horizontal. Since one of these components, the fault-parallel horizontal velocity, is approximately zero because the seismic station is aligned along-strike with the hypocenter (Figure 2), we just provide results for the other two components, vertical and fault-perpendicular horizontal. For the vertical component of station motion, the mismatch in PGV is $4 \%$ for TPV12-2D, 8\% for TPV13-2D, 17\% for TPV12-3D, and 7\% for TPV13-3D (Table 3). For the fault-perpendicular horizontal component of station motion, the mismatch in PGV is $8 \%$ for TPV12-2D, 5\% for TPV13-2D, 14\% for TPV12-3D, and $2 \%$ for TPV13-3D (Table 4). All of these mismatch values are less than $20 \%$.

\section{SUMMARY AND CONCLUSIONS}

In situations where seismological data is rare or nonexistent, computer simulations may be used to predict ground motions caused by future earthquakes. This is particularly practical in the case of extreme ground motions, where engineers of special buildings may need to design for an event that has not been historically observed but which may occur in the far-distant future. Once the simulations have been performed, however, they still need to be tested. The SCEC-USGS dynamic rupture code verification exercise provides a testing mechanism

\section{TABLE 4}

PGV-Horizontal, Fault-Perpendicular (also see Figure 4). All seismograms were first filtered with an acausal twopoles, two-passes, 3-Hz lowpass Butterworth filter.

\begin{tabular}{|lcccc|}
\hline Benchmark & $\begin{array}{c}\text { PGV- } \\
\text { Maximum } \\
(\mathbf{m} / \mathbf{s})\end{array}$ & $\begin{array}{c}\text { PGV- } \\
\text { Minimum } \\
(\mathbf{m} / \mathbf{s})\end{array}$ & $\begin{array}{c}\text { PGV- } \\
\text { Average } \\
(\mathbf{m} / \mathbf{s})\end{array}$ & $\begin{array}{c}\text { Mismatch } \\
\text { (equation } \\
\mathbf{1})\end{array}$ \\
\hline $\begin{array}{l}\text { TPV12-2D } \\
\text { elastic }\end{array}$ & 3.50 & 3.22 & 3.39 & $8 \%$ \\
$\begin{array}{l}\text { TPV13-2D } \\
\text { plastic }\end{array}$ & 3.12 & 2.96 & 3.04 & $5 \%$ \\
$\begin{array}{l}\text { TPV12-3D } \\
\text { elastic }\end{array}$ & 2.48 & 2.17 & 2.26 & $14 \%$ \\
$\begin{array}{l}\text { TPV13-3D } \\
\text { plastic }\end{array}$ & 2.34 & 2.29 & 2.31 & $2 \%$ \\
\hline
\end{tabular}

Results: The peak ground velocities from the 2D simulations are larger than those from the 3D simulations.

for simulations that involve spontaneous earthquake rupture. We have performed this examination for the specific computer code that was used to predict maximum possible ground motion near Yucca Mountain. Our SCEC-USGS group exercises have demonstrated that the specific computer code that was used for the Yucca Mountain simulations produces similar results to those produced by other computer codes when tackling the same science problem. We also found that the 3D ground motion simulations produced smaller ground motions than the $2 \mathrm{D}$ simulations. $\mathbf{K}$

\section{ACKNOWLEDGMENTS}

Funding for the Rupture Dynamics Code Verification Exercise has come from the Southern California Earthquake Center (funded by NSF Cooperative Agreement EAR-0106924 and USGS Cooperative Agreements 02HQAG0008), internal USGS Earthquake Hazards Program funds, the U.S. Department of Energy Extreme Ground Motions project, and Pacific Gas and Electric Company. Thanks to Tom Jordan for his support of this project and to Phil Maechling for helping us with the logistics of the code-validation Web site. This manuscript benefited from helpful reviews by $S R L$ reviewer Peter Moczo and USGS internal reviewers David Boore and Woody Savage. This is SCEC contribution number 1473.

\section{REFERENCES}

Aagaard, B. T., G. Anderson, and K. Hudnut (2004). Dynamic rupture modeling of the transition from thrust to strike-slip motion in the 2002 Denali fault, Alaska, earthquake. Bulletin of the Seismological Society of America 94 (6B), S190-S201; doi:10.1785/0120040614.

Ampuero, J.- P. (2009). Notes on modeling earthquake dynamics with the spectral element method; http://www.gps.caltech.edu/ ampuero/ docs/fsem.pdf.

Andrews, D. J., T. C. Hanks, and J. W. Whitney (2007). Physical limits on ground motion at Yucca Mountain. Bulletin of the Seismological Society of America 97 (6), 1,771-1,792; doi:10.1785/0120070014. 
Barall, M. (2009). A grid-doubling finite-element technique for calculating dynamic three-dimensional spontaneous rupture on an earthquake fault. Geophysical Journal International 178, 845-859; doi:10.1111/j.1365-246X.2009.04190.x.

Bechtel SAIC Company (2004). Development of Earthquake Ground motion Input for Preclosure Seismic Design and Postclosure Performance Assessment of a Geologic Repository at Yucca Mountain, $N V$. MDL-MGR-GS-000003 REV 01, November 2004, 1,022 pp.

Bechtel SAIC Company (2005). Peak Ground Velocities for Seismic Events at Yucca Mountain, Nevada. ANL-MGR-GS-000004 REV 00, February 2005, $186 \mathrm{pp}$.

CRWMS M\&O (Civilian Radioactive Waste Management System Management and Operation Contractor) (1998). Probabilistic Seismic Hazard Analyses for Fault Displacement and Vibratory Ground Motion at Yucca Mountain, Nevada. Vols. 1-3. Las Vegas, Nevada, Milestone SP32IM3.

Duan, B. (2008). Effects of low-velocity fault zones on dynamic ruptures with nonelastic off-fault response. Geophysical Research Letters 35, L04307; doi:10.1029/2008GL033171.

Duan, B. (2010). Role of initial stress rotations in rupture dynamics and ground motion: A case study with implications for the Wenchuan earthquake. Journal of Geophysical Research 115, B05301; doi:10.1029/2009JB006750.

Dunham, E. M., D. Belanger, L. Cong, and J. E. Kozdon (forthcoming). Earthquake ruptures with strongly rate-weakening friction and off-fault plasticity: Planar faults. Submitted to Bulletin of the Seismological Society of America.

Hanks, T. C., N. A. Abramson, J. W. Baker, D. M. Boore, M. Board, J. N. Brune, C.A. Cornell, and J. W. Whitney (the Extreme Ground Motion Committee) (forthcoming). Extreme Ground Motions and Yucca Mountain. USGS Open-File Report.

Hanks, T. C., N. Abrahamson, M. Board, D. Boore, J. Brune, and A. Cornell (2006). Workshop on Extreme Ground Motion at Yucca Mountain. USGS Open-File Report OF2006-1277.

Hanks, T. C., I. J. Winograd, R. E. Anderson, T. E. Reilly, and E. P. Weeks (1999). Yucca Mountain as a Radioactive-Waste Repository. USGS Circular 1184, 19 pp.

Harris, R.A. (2004). Numerical simulations of large earthquakes: Dynamic rupture propagation on heterogeneous faults. Pure and
Applied Geophysics 161 (11/12), 2,171-2,181; doi:10.1007/s00024004-2556-8, 2004.

Harris, R. A., M. Barall, R. Archuleta, E. Dunham, B. Aagaard, J. P. Ampuero, H. Bhat, et al. (2009). The SCEC/USGS dynamic earthquake rupture code verification exercise. Seismological Research Letters 80 (1), 119-126; doi:10.1785/gssrl.82.5.119.

Kaneko, Y., N. Lapusta, and J.-P. Ampuero (2008). Spectral element modeling of spontaneous earthquake rupture on rate and state faults: Effect of velocity-strengthening friction at shallow depths. Journal of Geophysical Research 113, B09317; doi:10.1029/2007JB005553.

Kase, Y., and K. Kuge (2001). Rupture propagation beyond fault discontinuities: Significance of fault strike and location. Geophysical Journal International 147, 330-342; doi:10.1046/j.1365246X.2001.00533.x

Kostrov, B. V. (1964). Self-similar problems of propagation of shear cracks (tangential rupture crack propagation in medium under shearing stress). Journal of Applied Mathematics and Mechanics $\mathbf{2 8}$ (5), 1,077-1,087.

Ma, S. (2009). Distinct asymmetry in rupture-induced inelastic strain across dipping faulting: An off-fault yielding model. Geophysical Research Letters 36, L20317; doi:10.1029/2009GL040666.

Ma, S., and D. J. Andrews (2010). Inelastic off-fault response and three-dimensional earthquake rupture dynamics on a strikeslip fault. Journal of Geophysical Research 115, B04304; doi:10.1029/2009JB006382.

Madariaga, R. (2007). Seismic source theory. In Treatise on Geophysics, vol. 4, chapter 2, ed. H. Kanamori, 59-82. Amsterdam and Boston: Elsevier.

Winograd, I. J. (1974). Radioactive waste storage in the arid zone. Eos, Transactions, American Geophysical Union 55 (10), 884-894.

\author{
U.S. Geological Survey \\ Mail Stop 977 \\ 345 Middlefield Road \\ Menlo Park, California 94025 U.S.A. \\ harris@usgs.gov \\ (R.A.H.)
}

